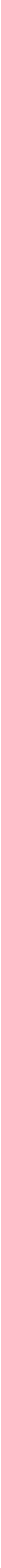




\title{
Método experiencial e avaliação em profundidade: novas perspectivas em políticas públicas
}

\author{
Experiential method and in-depth \\ evaluation: new perspectives in public \\ policies
}

* Lea Corvalho Rodrigues

\begin{abstract}
Resumo
O artigo apresenta duas propostas de avaliação de políticas públicas que se interconectam. A desenvolvida por Raul Lejano (2012), centrada na noção de experiência, e a desenvolvida por Lea Rodrigues (2008, 2011a) com foco em análise de categorias do entendimento, noções de tempo (percursos e trajetória) e espaço (territorialidade). Apresenta-se as duas propostas e, em seguida, de forma esquematizada, seus pontos de conexão e diferenciação. Por fim, se tomará um setor específico das políticas públicas, o turismo como estratégia de desenvolvimento, e se apresentarão alguns aportes analíticos com base nas referidas propostas.
\end{abstract}

Palavras-chave: políticas públicas, avaliação em profundidade, método experiencial.

\begin{abstract}
This article presents two interconnected proposals for evaluation of public policies: the onedeveloped by Raul Lejano (2012), centered on the notion of experience and the one developed by Lea Rodrigues (2008, 2011a), focused on notions of time (pathways, trajectories) and space (territoriality). The article presents those proposals and, in a schematic way, their points of connection and differentiation. Finally, a specific sector of public policies will be taken, tourism as a development strategy, and some analytical inputs will be presented based on these proposals.
\end{abstract}

Keywords: public policies, in-depth evaluation, experiential method. 


\section{Introdução}

O objetivo deste artigo é abordar duas propostas de avaliação de políticas públicas que se interconectam: i) a desenvolvida por Raul Lejano (2012), centrada na noção de experiência e na articulação de métodos e técnicas quantitativos e qualitativos (surveys, etnografia, imagens); e, ii) a desenvolvida por Lea Rodrigues (2008, 2011a), que privilegia a interpretação das categorias de entendimento presentes nas políticas, nos discursos institucionais e nos depoimentos dos beneficiários das políticas; as noções de tempo (percursos, trajetórias) e espaço (territorialidade), sendo uma proposta de caráter eminentemente qualitativo, mas que não descarta a utilização de dados quantitativos.

Para melhor compreensão das propostas acima elencadas serão apresentados, no plano empírico, indicativos para a operacionalização do modelo experiencial aliado à proposta de avaliação em profundidade. Trata-se do estudo avaliativo de um projeto de implementação de Parceria Público Privada (PPP) no Parque Nacional de Jericoacoara (PNJ), dentro dos objetivos da Política Nacional de Turismo (PNT) e da Política Nacional do Meio Ambiente.

Em primeiro lugar serão apresentados os pressupostos e referenciais teóricos que sustentam os dois modelos de avaliação acima referidos. Em seguida, de forma sintética, serão apresentados os dados sistematizados da análise de conteúdo do Plano de Manejo para o referido Parque Nacional, das diretrizes do Sistema Nacional de Unidades de Conservação (SNUC) e da PNT, no que se refere a um dos pontos considerados centrais para o início de estudo e avaliação de uma política, a coerência interna das bases conceituais que orientam as políticas e da formulação das propostas (Rodrigues, 2008). Finalmente, a partir de dados secundários (coletados em periódicos e sites institucionais) e primários (observação de audiências e realização de entrevistas abertas), bem como do contexto de formulação da PNT e da proposta do projeto de PPP, serão expostos os principais indicativos quanto à coerência ou contradição entre bases conceituais presentes nos textos oficiais (política, Plano de Manejo, proposta de PPP) e os resultados vindos da pesquisa empírica, de caráter etnográfico. Entendese que, mesmo tendo em conta o atual estágio da pesquisa, ainda em andamento, esses resultados já permitirão vislumbrar a pertinência e o potencial dos modelos experiencial e de avaliação em profundidade, aqui apresentados, para a avaliação de políticas públicas.

\section{Metodologia: dois modelos de avaliação}

\section{$\bigcirc$ modelo experiencial}

O modelo experiencial, apresentado por Lejano (2012), é uma proposta inovadora porque fornece novos referenciais teórico-metodológicos capazes de integrar as perspectivas quantitativas e qualitativas de análise, de forma a alcançar um nível mais 
profundo de compreensão de questões não resolvidas pelos métodos tradicionais. Polêmica, porque o autor coloca em questão os modelos positivistas de análise que há décadas orientam os estudos na área de políticas públicas, afirmando e mostrando os limites de seu poder explicativo. $\mathrm{O}$ argumento central do autor é que os métodos clássicos - que partem de uma lógica linear, calcada em testes de hipóteses-, centrados na mensuração do objeto de estudo, constrangem a aprendizagem e o entendimento a um modo predeterminado que impede a compreensão da política na forma como ela realmente ocorre e é vivida, experienciada, ele diz, por uma multiplicidade de atores' 1 .

Para superar os limites dos modelos de análises de políticas vigentes na atualidade, Lejano propõe, em primeiro lugar, que uma análise de políticas deve considerar as múltiplas dimensões da experiência e do entendimento, atentando para a complexidade dos fenômenos - seu caráter processual, contextual, dinâmico e flexível, só apreensível pelo entendimento de sua realização na prática. Esta perspectiva dá à noção de experiência um lugar central nas formulações teórico-metodológicas propostas pelo autor. Isto implica que o desenho da avaliação muda, não comportando mais um modelo linear de teste de hipóteses, que tenha como objetivo apenas verificar se aquilo que foi colocado como meta da política se cumpriu (efetividade), ou se a relação custos benefícios é positiva (eficiência) ou, ainda, se os resultados obtidos foram positivos (eficácia).

Para comparar os modelos que o autor classifica como positivistas com a sua proposta experiencial, apresentamos os quadros abaixo, construídos a partir de dimensões epistemológicas (Quadro 1) e eixos-analíticos (Quadro 2).

Quadro 1- Modelos Positivista e Experiencial

\begin{tabular}{|c|c|c|}
\hline Dimensão & Modelo Positivista & Modelo Experiencial \\
\hline \multirow[t]{3}{*}{ Lógica } & Linear & Não linear \\
\hline & Hipóteses isoladas do empírico & Interação pesquisador /empiria \\
\hline & Teste de hipóteses & Teoria emerge da prática \\
\hline $\begin{array}{l}\text { Natureza do } \\
\text { conhecimento } \\
\text { alcançado }\end{array}$ & $\begin{array}{l}\text { Resultado de análise de dados } \\
\text { estatísticos (survey). }\end{array}$ & $\begin{array}{l}\text { Multidimensional: diferentes tipos de } \\
\text { dados e informações. }\end{array}$ \\
\hline \multirow[t]{3}{*}{ Análise } & Teste de hipóteses & Hermenêutica -Holística \\
\hline & $\begin{array}{l}\text { Resultado final: correlação ou não } \\
\text { com as hipóteses; }\end{array}$ & $\begin{array}{l}\text { Integração das diferentes dimensões } \\
\text { contempladas }\end{array}$ \\
\hline & Critérios: replicabilidade e confiança. & $\begin{array}{l}\text { Critérios: autenticidade da descrição da } \\
\text { política como experiência }\end{array}$ \\
\hline \multirow[t]{2}{*}{ Objetivos } & Prova estatística & $\begin{array}{l}\text { Compreensão ampla e processual da } \\
\text { dinâmica da política }\end{array}$ \\
\hline & Respostas pontuais & Possibilidade de ação \\
\hline
\end{tabular}

Fonte: Elaboração própria a partir de Lejano (2012, p.219-223)

O quadro acima émarcado pelo forte contraste entre os dois modelos, com posições opostas em todas as dimensões elencadas, respeitando os principais argumentos 
tecidos pelo autor, ainda que saibamos que o campo de estudos sobre avaliação de políticas públicas comporta propostas intermediárias, como, por exemplo, os modelos construtivistas e pós-construtivistas ${ }^{2}$

Contrapondo os dois modelos, Lejano mostra como o primeiro é pautado em uma apreensão linear do processo, partindo de um conjunto de hipóteses e terminando com um teste destas mesmas hipóteses, construídas isoladamente da situação empírica e resultando num conhecimento confinado a um tipo restrito de dados, geralmente dados estatísticos. A proposta do autor, de forma contrária, é não linear, as hipóteses surgindo de um processo circular entre a situação empírica e a reflexão conjunta entre pesquisador e grupo pesquisado, nas quais a teoria emerge da prática e os dados provêm de fontes diversificadas de informação: entrevistas, surveys, observações de campo, recursos audiovisuais, grupos focais.

Enquanto no primeiro modelo os critérios são de confiança e replicabilidade, no segundo eles são fundados nos critérios de profundidade e complexidade. Enquanto, no primeiro, os resultados restringem-se à confirmação ou não das hipóteses, no segundo eles se constituem na fusão de diferentes linhas de informação. Enquanto os objetivos, no primeiro, são aferição de resultados pontuais, medir e comprovar, no segundo caso eles visam, sobretudo, possibilitar a ação: conhecer e compreender.

O importante é notar que para superar os limites dos modelos vigentes de análises de políticas, Lejano (2012) propõe a necessidade, em primeiro lugar, de considerar as múltiplas dimensões da experiência e do entendimento, atentando para a complexidade dos fenômenos - seu caráter processual, contextual, dinâmico e flexível só apreensível pelo entendimento de sua realização na prática. Esta perspectiva dá à noção de experiência um lugar central nas formulações teóricas e metodológicas propostas pelo autor. Assim, ele afirma que, se nós quisermos compreender porque políticas e instituições funcionam ou falham, precisamos penetrar no que são essas entidades realmente, não nos limitando a perceber como elas estão constituídas formalmente. Desta perspectiva, segundo Lejano, as fronteiras são borradas, flexíveis, intercambiáveis e não formais. De forma similar, papeis e identidades são múltiplos e intercambiáveis.

Afirma ainda Lejano que o grau de coerência de uma política permite avaliar sua durabilidade no tempo. $\mathrm{O}$ autor considera central, para se atingir este objetivo, que as ideias de contexto e particularidade sejam o guia do pesquisador, ou seja, advoga a valorização do lugar e de seus recursos. Este seria um grande diferenciador em relação às formas tradicionais (positivistas) de análise que, segundo ele, partem da homogeneidade de conceitos e, em consequência, as análises falham por não capturarem a complexidade inerente aos programas reais; ou seja, o autor chama a atenção para a diferença entre a política ou programa nos planos abstrato e empírico. 


\section{A proposta da avaliação em profundidade}

Pode-se dizer que a proposta de uma avaliação em profundidade segue o modelo experiencial em todas as dimensões elencadas no Quadro 1 apresentado no tópico anterior, com a diferença de não se preocupar com a elaboração de hipóteses, mas considerar apenas, inicialmente, alguns pressupostos inferidos da imersão em campo, de caráter exploratório. Sua proposta é qualitativa, com inspiração etnográfica, mas admite a integração com dados quantitativos e secundários. O quadro acima procurou sintetizar os seus principais eixos analíticos, comparando, dessa perspectiva, com os modelos clássicos (positivistas) de análise, mostrando, assim, suas proximidades e diferenças.

A proposta de uma avaliação em profundidade toma basicamente quatro grandes eixos de análise: conteúdo da política e/ou do programa, contemplando sua formulação, bases conceituais e coerência interna; trajetória institucional; espectro temporal e territorial abarcado pela política ou programa e análise de contexto de formulação dos mesmos (Rodrigues, 2008).

As primeiras condições para a realização de uma avaliação em profundidade, como exposto em Rodrigues (2008), foram de que a mesma conseguisse ser ao mesmo tempo extensa, detalhada, densa, ampla e multidimensional, o que exigiria uma abordagem multi e interdisciplinar. Estes elementos já situam a proposta como crítica aos modelos positivistas de análise, centrados em um saber fragmentado, disciplinar e especializado, afirmando, de outra forma, a incapacidade dos paradigmas dominantes vigentes em fornecer soluções para problemas e fenômenos cada vez mais complexos ${ }^{3}$.

Assim, a exigência de que a avaliação seja extensa e ampla indica que uma avaliação em profundidade não poderá se restringir a um olhar focado apenas na averiguação do cumprimento das metas propostas pela política e seus resultados, ou nos itens priorizados por um programa, bem como tão somente no atendimento às suas diretrizes. Quanto ao aspecto da densidade, a referência fundamental é ao principal pressuposto das abordagens interpretativas, seguindo as proposições de Geertz (1978) da busca de significados, no caso os significados da política para os que as formulam, executam ou vivenciam. Isto implica, em primeiro lugar, que a pesquisa qualitativa ganha destaque nesta abordagem. No plano prático, em suma, a avaliação não pode se restringir à análise de dados estatísticos resultantes da coleta de dados por meio de questionários, ainda que estes contemplem perguntas abertas e forneçam ao entrevistado espaço para colocar suas ideias. Isto porque a apreensão de significados exige a realização de entrevistas aprofundadas e abertas; ou seja, entrevistas que não conduzam o entrevistado à resposta e que não Ihe cerceiam o campo de reflexão ao lhe apresentar perguntas que em si já pressupõem razões para o sucesso ou não da política ou do programa em estudo, para a ocorrência de situações constatadas quando da realização de observações em campo, ou mesmo para esclarecimento de 
dados coletados por meio de questionários ou provindos de estatísticas oficiais. Uma entrevista aberta e aprofundada de qualidade é aquela que resulta em informações e reflexões novas, na maioria das vezes sequer imaginadas pelo pesquisador. A riqueza dessa modalidade de entrevista é que ela fornece ao pesquisador os elementos importantes para a análise pelo cotejamento das ideias, informações e reflexões, também elas interpretações, tecidas pelos próprios entrevistados. Como bem afirma Geertz (1978), a descrição densa é mais do que métodos e técnicas de investigação, referindo-se em especial ao esforço intelectual do pesquisador na busca dos sentidos e significados que emanam da situação em estudo, que inclui, evidentemente, os dados coletados; mas estes dados não falam por si mesmos.

Quadro 2 - Modelos Clássicos e Contemporâneos na Avaliação de Políticas Públicas

\begin{tabular}{|c|c|c|}
\hline \multirow[t]{2}{*}{ Eixos Analíticos } & Modelos Clássicos (Positivistas) & Avaliação em Profundidade \\
\hline & $\begin{array}{l}\text { Lógica interna do programa (modelo } \\
\text { lógico: insumos, processos, resultados); }\end{array}$ & $\begin{array}{l}\text { Análise das bases conceituais do } \\
\text { programa e da política: paradigmas } \\
\text { orientadores; conceitos e noçôes centrais; } \\
\text { concepções e valores (coerência interna); }\end{array}$ \\
\hline \multirow[t]{2}{*}{ Conteúdo } & $\begin{array}{l}\text { Identificação dos objetivos e } \\
\text { resultados esperados } \\
\text { Teoria do Programa: hipóteses s/ } \\
\text { resultados esperados }\end{array}$ & $\begin{array}{l}\text { Análise da formulação do programa e } \\
\text { da política: objetivos, critérios, dinâmica } \\
\text { de implantação, acompanhamento e } \\
\text { avaliação (coerência). }\end{array}$ \\
\hline & $\begin{array}{l}\text { Lógica externa do programa / } \\
\text { Articulação: execução e efeitos } \\
\text { esperados }\end{array}$ & \\
\hline Contexto & $\begin{array}{l}\text { Referido apenas à abrangência da } \\
\text { Avaliação: nível macro ou micro; global } \\
\text { ou setorial }\end{array}$ & $\begin{array}{l}\text { Contexto da formulação do programa e } \\
\text { da política: Análise do momento político } \\
\text { e das condições socioeconômicas em que } \\
\text { foram formulados } \\
\text { Contextos da trajetória do programa } \\
\text { / política: esferas institucional e local } \\
\text { Contextos do processo (no tempo) do } \\
\text { programa/política: diferentes contextos } \\
\text { podem alterar conteúdos e processos }\end{array}$ \\
\hline $\begin{array}{l}\text { Trajetória/ } \\
\text { Temporalidade }\end{array}$ & $\begin{array}{l}\text { Trajetória: não contemplado } \\
\text { Temporalidade: restrita à perspectiva } \\
\text { temporal da avaliação }\end{array}$ & $\begin{array}{l}\text { Grau de coerência ou dispersão dos } \\
\text { objetivos da política ou programa } \\
\text { conforme o trânsito pelas vias } \\
\text { institucionais, ao longo do tempo. }\end{array}$ \\
\hline $\begin{array}{l}\text { Espectro } \\
\text { territorial/ } \\
\text { Temporalidade }\end{array}$ & $\begin{array}{l}\text { Segmentação por níveis e etapas de } \\
\text { avaliação: abrangência (macro, micro, } \\
\text { setorial, local) e tipo da avaliação (ex- } \\
\text { ante, implementação, ex-post). }\end{array}$ & $\begin{array}{l}\text { Configuração temporal e territorial } \\
\text { do percurso da política: confronto das } \\
\text { propostas e objetivos da política com as } \\
\text { especificidades locais e sua historicidade } \\
\text { (importância da dimensão cultural) }\end{array}$ \\
\hline
\end{tabular}

Fonte: Holanda (2006); Rodrigues (2008)

Os quatro eixos analíticos apresentados: 1) conteúdo da política e/ou do programa, contemplando: formulação, bases conceituais e coerência interna; 2) trajetória institucional; 3) espectro temporal e territorial abarcado pela política/programa; e, 4) análise de contexto de formulação da política e/ou do programa são os norteadores desta proposta de avaliação em profundidade. 
Quanto ao primeiro ponto, análise de conteúdo da política ou programa, a proposta considera três dimensões como centrais: i) formulação da política, com atenção aos objetivos presentes nos documentos de sua institucionalização e aos critérios apresentados para a sua implantação, acompanhamento e avaliação; ii) os conceitos, ideias, noções e valores que conformam os paradigmas orientadores da política e que formam um corpo teórico que lhes dá sustentação; iii) o cotejamento dessa base conceitual com os critérios estabelecidos, ou seja, verificação da coerência interna da política no que diz respeito à disponibilidade de todos os mecanismos de efetivação da política segundo sua proposta teórica e sua base conceitual. Este tópico foi pensado, na prática, como sendo o exame do material institucional apenas, mas em Rodrigues (2011a) considera-se como mais produtivo aliar a análise de conteúdo da política à noção de trajetória, de forma que a apreensão das bases conceituais de uma política ou programa ganha maior consistência quando, além do material institucional, o pesquisador contempla entrevistas com os sujeitos que participaram do processo de formulação da política em seus diferentes momentos.

Quanto à análise de contexto da formulação da política, esta perspectiva prioriza o levantamento de dados sobre o momento político e as condições socioeconômicas, com atenção às articulações entre as esferas local, regional, nacional, internacional, e mesmo transnacional, quando é o caso. Ganha destaque, nesse eixo analítico, a apreensão do modelo político/econômico vigente no país e a articulação da política ou programa a outras políticas e/ou programas. Ou seja, considerar a política ou programa como parte de um conjunto de ações que expressa, de forma mais abrangente, um modo de conceber a política, em seu sentido mais amplo, contemplando o econômico, o social, o cultural e a definição dos caminhos para o país. Assim, a afirmação subjacente a esta proposição é que: para compreender a dinâmica de políticas implementadas em diferentes momentos históricos, concebidas a partir de modelos político-econômicosociais específicos, é relevante perceber como são acionados elementos de ordem simbólica - étnicos e identitários; valores morais, cívicos e éticos; ideias e símbolos articulados a ideologias do progresso e da modernização, dentre outros.

O terceiro componente desta proposta avaliativa, o acompanhamento da trajetória da política, é considerado um dos mais importantes para o entendimento sobre como, localmente, no ato da implementação de ações concernentes a políticas gestadas em esferas superiores, as diretrizes são compreendidas e reinterpretadas; principalmente quando, em razão dos processos de descentralização, é fornecida autonomia às esferas regionais e locais. Por meio desta análise é possível perceber descompassos entre as concepções presentes na formulação da política e aquelas acionadas quando da sua implementação; bem como detectar mudanças ocorridas durante o trajeto da política pelas vias institucionais. Gussi (2008), ao propor um lugar de destaque para a trajetória institucional no processo de avaliação de políticas, se respalda na noção de trajetória desenvolvida por Pierre Bourdieu, no ensaio A ilusão Biográfica, quando, como afirma o autor, Bourdieu desconstrói a ideia de que uma trajetória de vida seja um processo 
linear que se pode apreender de uma só vez, como se fosse um todo coerente. E assim como Bourdieu se debruça sobre essa noção para pensar o processo de uma vida, Gussi transpõe o conceito de trajetória de vida para as instituições, afirmando que elas, assim como uma vida, podem ser apreendidas pelos processos relativos aos múltiplos trajetos (deslocamentos) e posições que estas ocupam no campo social ao longo do tempo.

Como evidencia, ainda, o Quadro 2, o pressuposto desta perspectiva de avaliação é que não se pode isolar a avaliação de programas ou projetos da análise minuciosa da política (seus textos de lei e normatização, com ênfase nas concepções, paradigmas e mecanismos práticos apontados pela política) bem como um destaque às dimensões temporal e territorial. Nesse sentido, o último eixo analítico apresentado, o espectro temporal e territorial, que diz respeito ao percurso de uma política pelas vias institucionais e espaços socioculturais, ao longo do tempo de sua implementação, está intimamente articulado ao da trajetória institucional da política. Este último trata dos deslocamentos de uma política por espaços políticos, econômicos e socioculturais distintos, uma vez que comporta, não apenas do ponto de vista macro estrutural, o trânsito pelas esferas federal, estadual e municipal, mas a apreensão e efetivação da política em contextos distintos; sujeita, portanto, a uma variada gama de apropriações e interferências - conforme os interesses, jogos de poder e forças políticas locais -, podendo levar a resultados distintos, bem como revelar inadequações na forma como a mesma foi pensada, formulada e implantada, em razão de particularidades que dizem respeito à dimensão sociocultural local e/ou regional. A esse respeito, vale destacar a contribuição de Gonçalves (2008), como também de Gonçalves e Santos (2010) ao afirmarem a necessidade de construção de indicadores socioculturais. Gonçalves apresenta como condição para a formulação de indicadores socioculturais o mapeamento junto aos beneficiários das políticas, que ocupam territórios específicos, das seguintes dimensões: i) economia (arranjos produtivos e cadeias produtivas locais); ii) relações de poder locais, em articulação com as esferas estadual e federal; iii) cultura, referindo-se aos valores, tradições e referenciais identitários locais; iv) geografia, atentando para as particularidades locais quanto às condições físicas e climáticas; v) redes de proteção social existentes nas localidades estudadas (por exemplo, as políticas nas área de saúde, inserção social e redução da pobreza); vi) concepções e projetos de desenvolvimento local existentes, e, vii) sistema educacional.

Considera-se, do ponto de vista de uma avaliação em profundidade, que tanto as propostas de Gussi (2008) como as de Gonçalves (2008) e Gonçalves e Santos (2010), acima apresentadas, são bastante inovadoras e apontam possibilidades metodológicas e analíticas instigantes. E como toda proposta original, esta também demanda uma continuada reflexão sobre suas possibilidades de realização prática e sobre as necessidades de formulações de ordem epistemológica, bem como de mecanismos teórico-metodológicos que Ihe confiram sustentação e respondam às 
muitas questões que se colocam ao pesquisador que pretende se inserir ou dialogar com esta linha de pensamento.

\section{Indicativos para operacionalização da proposta}

Para uma melhor compreensão da operacionalização da proposta aqui apresentada, a junção do modelo experiencial e a avaliação em profundidade, tomase como objeto de reflexão uma situação em especial, a proposição de uma Parceria Público Privada (PPP) para atuar no Parque Nacional de Jericoacoara (PNJ), no estado do Ceará, apresentada em 2013 pelo Ministério do Planejamento Orçamento e Gestão (MPOG) em articulação com o Ministério do Meio Ambiente (MMA).

Em 28 de novembro de 2013 foi realizada a primeira reunião ordinária do Conselho Consultivo do Parque Nacional de Jericoacoara - CONPARNA, para apresentação de estudos preliminares realizados por uma empresa de consultoria contratada pelo Instituto Chico Mendes de Conservação da Biodiversidade (ICMBio) para subsidiar os editais de concessões à iniciativa privada de infraestruturas e serviços no PNJ, na modalidade PPP. Segundo informações do próprio ICMbio, em seu site oficial, a proposta teve boa acolhida dos conselheiros e a apresentação oficial dos estudos ocorreria em janeiro de 2014.

A reunião prevista para janeiro foi adiada para 12 de fevereiro de 2014, quando os representantes do ICMBio, do MPOG e o consultor da empresa IDOM, contratada pelo ICMBio, apresentaram os resultados de um Estudo de Demanda/Viabilidade Econômica, Estudo Sócio Ambiental e Estudo de Engenharia e Arquitetura efetuado com a finalidade de subsidiar o processo de efetivação da concessão à iniciativa privada da operação dos serviços e infraestruturas no PNJ. Desta vez a reunião ocorreu com massiva presença dos moradores da Vila de Jericoacoara, bem como das autoridades locais, e os debates foram geradores de muita polêmica em relação à forma como seriam afetados por estas medidas os que vivem do turismo na localidade e adjacências: os moradores, os turistas de menor poder aquisitivo que teriam que pagar para permanecer na vila, e o meio ambiente, caso sejam construídos hotéis e restaurantes como previsto nos estudos apresentados ${ }^{4}$. Além do mais, a previsão de construção de passarelas, lojas e mirante na região da Pedra Furada, entendiam os moradores que descaracterizaria completamente o turismo que se pratica em Jericoacoara, que poderia ser classificado como um turismo ecológico avesso às formas padronizadas do turismo tradicional ${ }^{5}$.

Frente a esta polêmica, entendeu-se que para estudar os efeitos desta proposta sobre a população local e ambiente a partir das perspectivas de análise e avaliação aqui apresentadas, seria necessário:

i) realizar um amplo e profundo levantamento e análise da legislação ambiental e das políticas de turismo ${ }^{6}$ e meio ambiente vigentes, bem como uma análise do Plano de Manejo de Jericoacoara, apreendendo as concepções presentes 
nas políticas, atentando à sua coerência interna e à existente entre estas e as particularidades do Plano de Manejo e das propostas específicas da PPP. Em seguida, identificar as categorias centrais presentes nesses documentos, o sentido que é dado a elas e as possíveis contradições ou elementos explicativos de situações encontradas em pesquisa, sobretudo as categorias sociedade, natureza, cultura, ambiente, que podem portar significados distintos nos diferentes textos institucionais. Isto é o que se denominou Análise de Conteúdo na proposta da avaliação em profundidade (Rodrigues, 2008);

ii) Compreender o processo de implementação das ações de concessão do parque à iniciativa privada, acompanhando as audiências e reuniões que ocorrerem com respeito às mudanças anunciadas. Esta tarefa seria feita com recurso metodológico à análise de situações sociais, como proposto pelos antropólogos Gluckman (1987) e Velsen (1987);

iii) Compreender a dinâmica social local, procedendo a um levantamento etnográfico sobre a Vila de Jericoacoara com respeito à infraestrutura turística, de comunicações, saúde, educação, segurança e comércio, participando das atividades sociais cotidianas. Quanto a este aspecto, são centrais as variáveis tempo e espaço e a noção de territorialidade;

iv) Apreensão do processo de mudanças, ao longo do tempo, coletando dados primários, de campo (observação in loco), e sobre o desenrolar dos acontecimentos, com a realização de entrevistas com os principais atores envolvidos: representantes da Vila de Jericoacoara no Conselho Consultivo, técnicos do MPOG, Mtur, MMA, ICMbio e população local, em sua diversidade. Para esta dimensão analítica é crucial a noção de processo e de trajetória da política.

v) Evidenciar as mudanças ocorridas na Vila de Jericoacoara, no município de Jijoca de Jericoacoara e no turismo ali praticado, no decorrer do processo, a partir do conjunto de etapas e procedimentos acima elencados. Novamente as noções de processo e trajetória são fundamentais para a percepção das mudanças em contextos e esferas institucionais distintos. A noção de experiência desenvolvida por Lejano (2012) também é central para o entendimento das mudanças de forma contextualizada e a partir da vivência dos sujeitos, sejam estes os técnicos administrativos, os gestores institucionais, sejam os habitantes das localidades estudadas empiricamente.

\section{Discussão da proposta}

As etapas de pesquisa, como acima apresentado, em acordo com o modelo experiencial de Lejano (2012), se valem de múltiplas metodologias, técnicas e procedimentos de pesquisa: i) survey para a população local; ii) entrevistas abertas com os sujeitos elencados; etnografia (observação participante, pesquisas intensivas 
de campo); registros fotográficos, fílmicos e elaboração de mapas cartográficos; análise de conteúdo dos documentos oficiais, do material proveniente de jornais e sites institucionais e não institucionais.

Sobre esta proposta, vale notar que, como alertei em Rodrigues (2008), embora há mais de uma década a etnografia venha ganhando espaço em vertentes interpretativas das áreas da administração e da avaliação de políticas públicas, há que se reconhecer que na própria antropologia, espaço institucional por excelência do exercício da prática etnográfica, existe um amplo campo de discussões e vasta literatura que expõe as divergências "sobre o estatuto da etnografia, sua abrangência analítica, formas menos ou mais legítimas de apresentação dos resultados e as especificidades da aplicação desse instrumental em situações diversas daquelas que foram vivenciadas pelos antropólogos clássicos" (p. 11). Por outro lado, é fato que a pesquisa de campo intensiva, de caráter etnográfico, é a que permite apreender de forma mais acabada a experiência dos sujeitos, ou seja, o entendimento sobre como a política é experienciada na prática, nos termos de Lejano (2012), ainda que o resultado final não seja exatamente uma etnografia. Como afirmam Peirano $(1995,2014)$ e Uriarte (2012) uma etnografia compreende uma formação em antropologia, a transposição da experiência de campo para o texto etnográfico e o diálogo profícuo com a teoria antropológica ${ }^{7}$.

Como parte da pesquisa de campo, de uma perspectiva antropológica ganha destaque o recurso metodológico à análise situacional (Velsen, 1987). Esta é um instrumental metodológico estratégico para a análise de situações como mobilizações coletivas, assembleias e fóruns e situações diversos que coloquem em interação diferentes agentes. Trata-se de mecanismo de tratamentos dos dados como forma de apreender processos sociais de forma contextualizada, situando gente, tempo e lugar, como diz o autor. Busca detectar as estratégias de escolha dos indivíduos, as estratégias de ação, a contradição entre normas e ação, os conflitos inerentes a uma situação e os mecanismos de resolução desses conflitos. É uma proposição crítica à análise estruturalista que toma as regras como sendo o comportamento de fato, vê a sociedade de forma homogênea e assim minimiza as variações, contradições e conflitos existentes, privilegiando a estabilidade social. Dessa forma ignora-se a questão da mudança. Em contraposição a esse tipo de análise, Velsen afirma que as regras nem sempre correspondem ao comportamento observado.

Para o entendimento do conflito socioambiental instaurado e o acompanhamento do processo de implementação da política de PPP, outro recurso metodológico importante diz respeito às contribuições da ecologia política (Little, 2006) para a apreensão da dinâmica do conflito, o que demanda: i) identificação e análise dos principais atores envolvidos no conflito; ii) identificação dos interesses e reivindicações em torno dos recursos naturais e do território; iii) análise dos atores e das distintas cotas de poder. 
Em acordo com a proposta de Rodrigues (2008), a atenção primeira deve ser dada ao material institucional, aos textos das políticas e dos demais documentos oficiais referidos à situação em estudo. Vale frisar, no entanto, que esta formulação se diferencia do uso do qualitativo feito pelas abordagens mais positivistas, que operam com a quantificação do qualitativo pela análise categórica; variações estas que estão já nos pressupostos ontológicos e epistemológicos que distinguem os respectivos modelos de análise. E quanto a este aspecto, a proposta está em acordo com as críticas feitas por Yanow (2000, 2003, 2004) e Yanow e Schwartz-Sea (2014) aos métodos qualitativos que reproduzem formas de classificação e análise de dados baseados nos modelos desenvolvidos na área das ciências naturais. Ao contrário do que ocorre nesses intentos de análise, os métodos qualitativos baseados na hermenêutica não iniciam a pesquisa com variáveis estabelecidas antecipadamente ou com hipóteses a serem testadas e confrontadas com os dados de campo. Na proposta hermenêutica a realidade informa ao pesquisador o que é primordial à análise, e ele, pesquisador, tem que estar aberto ao que observa, ouve e vivencia, pois é desta capacidade de imersão no campo que resulta uma boa ou má avaliação de uma política.

\footnotetext{
Notas

'Na mesma linha de pensamento encontram-se Yanow (2000, 2003, 2004) e Yanow e Schwartz-Sea (2014)

${ }^{2}$ Vide Guba e Lincoln (2011).

${ }^{3}$ Quanto a esta proposta multi e interdisciplinar, destaca-se o pensamento de Georges Gurdof, que propôs ao "novo pesquisador" situar-se entre os espaços disciplinares, descobrindo interrelações entre disciplinas próximas e distantes, repensando assim a sua própria prática e abrindo-se à proposição de novos caminhos na realização da pesquisa. (A respeito veja Alvarenga; Somerman; Alvarez , 2005).

${ }^{4} \mathrm{~A}$ audiência foi gravada em vídeo, disponibilizado na internet, mas a equipe de pesquisa contou com a participação de um de seus integrantes no evento. Assim, as informações resultam dessa observação no local e no calor dos acontecimentos.

${ }^{5}$ A expressão turismo tradicional refere-se ao turismo que se dá por meio de agências/pacotes de viagens, com suporte e infraestrutura local de alto padrão, planejamento de atividades, demarcação de horários, locais para visitação (roteiros), etc.

${ }^{6}$ Para subsídio à análise de conteúdo da Política Nacional de Turismo (PNT) vide Rodrigues (2011b).

${ }^{7}$ A este respeito vide, também, Goldman (2003), Magnani (2009, 2012); sobre o uso da etnografia na avaliação de políticas públicas vide Rodrigues (2015).
}

\section{Referências}

ALVARENGA, A. T.; SOMERMAN, A.; ALVAREZ, A. M. S. Congressos internacionais sobre transdisciplinaridade: reflexões sobre emergências e convergências de ideias e ideais na direção de uma nova ciência moderna. Saúde e Sociedade, vol.14, n.3, p.9-29, set-dez/2005.

GEERTZ, C. A interpretação das culturas, Rio de Janeiro: Zahar, 1978.

GLUCKMAN, M. Análise de uma situação social na Zululândia moderna. In: FELDMAN-BIANCO, B. (org.). Antropologia das Sociedades Contemporâneas - Métodos. São Paulo: Global, 1987.

GOLDMAN, M. Os tambores dos mortos e os tambores dos vivos. Etnografia, antropologia e política em Ilhéus, Bahia. Revista de Antropologia, São Paulo (USP), v.46 n², 2003. 
GONÇALVES, A. F. Políticas públicas, etnografia e a construção dos Indicadores socioculturais. AVAL Revista Avaliação de Políticas Públicas, ano I, vol.1, n.1, jan-jun, 2008.

GONÇALVES, A.; SANTOS, C. S. Indicadores locais de sustentabilidade e a avaliação de políticas sociais: contribuições para a gestão pública. Gestão pública: práticas e desafios. Vol. IV. Recife: Editora da UFPE, 2010.

GUBA, E. G.; LINCOLN, Y. S. Avaliação de quarta geração. Campinas, SP: Ed.Unicamp, 2011.

GUSSI, A. F. Apontamentos teóricos e metodológicos para a avaliação de programas de microcrédito. AVAL Revista Avaliação de Políticas Públicas, ano l, vol.1, n.1, jan-jun, 2008. p 29-39.

HOLANDA, N. Avaliação de Programas. Conceitos básicos sobre a avaliação "ex post" de programas e projetos. Fortaleza: ABC Editora, 2006.

LEJANO, R. Parâmetros para a análise de políticas: a fusão de texto e contexto. Campinas, SP: Ed. Arte Escrita, 2012.

LITTLE, E. Ecologia política como etnografia: um guia teórico e metodológico. Horizontes Antropológicos, Porto Alegre, ano 12, n. 25, p. 85-103, jan./jun. 2006.

MAGNANI, J. G. C. Etnografia como prática e experiência. Horizontes Antropológicos, ano 15, n.32, p.129-156, jul./dez. 2009.

. A etnografia é um método, não uma mera ferramenta de pesquisa que se pode usar de qualquer maneira. Revista de Ciências Sociais, Fortaleza, v.43, n.2, p.169-178, 2012.

PEIRANO, M. A favor da etnografia. Rio de Janeiro: Relume-Dumará, 1995. jul. /dez. 2014.

. Etnografia não é método. Horizontes Antropológicos, Porto Alegre, ano 20, n.42,

RODRIGUES, L.C. Propostas para uma avaliação em profundidade de políticas públicas sociais. AVAL Revista Avaliação de Políticas Públicas, ano l, vol.1, n.1, jan-jun, 2008, p. 07-15.

. Análises de conteúdo e trajetórias institucionais na avaliação de políticas públicas sociais: perspectivas, limites e desafios. CAOS - Revista Eletrônica de Ciências Sociais, n 16, mar. 2011a, p. 55-73.

. Diretrizes da Política Nacional de Turismo e subsídios para a sua avaliação. Revista Gestão Pública: Práticas e Desafios, Recife, v.ll, n.3, 2011b, p. 62-78.

. Etnografia e método etnográfico: limites e possibilidades de sua inserção no campo da avaliação de políticas públicas. VII SEMINÁRIO DA REDE BRASILEIRA DE MONITORAMENTO E AVALIAÇÃO, Belo Horizonte, 2015.

URIARTE, U.M. O que é fazer etnografia para os antropólogos. Ponto Urbe 11, São Paulo, (NAUUSP) 2012.

VELSEN, J. A análise situacional e o método de estudo de caso detalhado. In: FELDMANBIANCO, Bela (org.). Antropologia das Sociedades Contemporâneas - Métodos. São Paulo: Global, 1987.

YANOW, D. Translating Local Knowledge at Organizational Peripheries. British Journal of Management, v.15, p.9-25, London, 2004.

Interpretive Empirical Political Science: What Makes This Not a Subfield of Qualitative Methods. In: Qualitative Methods Section (APSA), 2003.

Conducting interpretive policy analysis. Newbury Park, CA: Sage, 2000.

YANOW, D.; SCHWARTZ-SHEA, PEREGRINE (eds.). Interpretation and Method: Empirical Research Methods and the Interpretive Turn. New York: M.E.Sharpe Inc., 2014. 